University of Wollongong

Research Online

Faculty of Engineering and Information

Faculty of Engineering and Information

Sciences - Papers: Part B

Sciences

2017

\title{
Compressive behavior of hybrid double-skin tubular columns with a large rupture strain FRP tube
}

Tao Yu

University of Wollongong, taoy@uow.edu.au

Shi Shun Zhang

University of Wollongong, shishun@uow.edu.au

Le Huang

University of Wollongong, Ih794@uowmail.edu.au

Chun Wa Chan

University of Wollongong, cwc263@uowmail.edu.au

Follow this and additional works at: https://ro.uow.edu.au/eispapers1

Part of the Engineering Commons, and the Science and Technology Studies Commons

Research Online is the open access institutional repository for the University of Wollongong. For further information contact the UOW Library: research-pubs@uow.edu.au 


\title{
Compressive behavior of hybrid double-skin tubular columns with a large rupture strain FRP tube
}

\author{
Abstract \\ A hybrid fiber-reinforced polymer (FRP)-concrete-steel double-skin tubular column (DSTC) consists of an \\ outer FRP tube and an inner steel tube, with the space in between filled with concrete. This paper presents \\ results from the first ever experimental study on hybrid DSTCs with a large rupture strain (LRS) FRP tube, \\ namely, polyethylene terephthalate (PET) FRP tube. The experimental program involved the testing of 12 \\ hybrid DSTC specimens with or without additional concrete inside the inner steel tube. The test results \\ confirmed the ample ductility of hybrid DSTCs with a PET-FRP tube despite the severe local buckling of \\ the inner steel tube at large axial deformations. The test results also suggested that the diameter-to- \\ thickness ratio of the inner steel tube is a more critical parameter in such DSTCs than in DSTCs with a \\ glass, carbon or aramid FRP outer tube.

\section{Disciplines} \\ Engineering | Science and Technology Studies

\section{Publication Details} \\ Yu, T., Zhang, S., Huang, L. \& Chan, C. (2017). Compressive behavior of hybrid double-skin tubular columns \\ with a large rupture strain FRP tube. Composite Structures, 171 10-18.
}




\title{
COMPRESSIVE BEHAVIOUR OF HYBRID DOUBLE-SKIN TUBULAR COLUMNS WITH A LARGE RUPTURE STRAIN FRP TUBE
}

\begin{abstract}
Tao Yu ${ }^{\mathrm{a}}$, Shishun Zhang ${ }^{\mathrm{b}}$, Le Huang ${ }^{\mathrm{c}}$ and Chunwa Chan ${ }^{\mathrm{d}}$
${ }^{a}$ Senior Lecturer, School of Civil, Mining and Environmental Engineering, Faculty of Engineering and Information Sciences, University of Wollongong, Northfields Avenue, Wollongong, NSW 2522, Australia (Corresponding author).Tel: +61 242213786 Email: taoy@uow.edu.au

${ }^{b}$ Lecturer, School of Civil, Mining and Environmental Engineering, Faculty of Engineering and Information Sciences, University of Wollongong, Northfields Avenue, Wollongong, NSW 2522, Australia ${ }^{c} \mathrm{PhD}$ Candidate, School of Civil, Mining and Environmental Engineering, Faculty of Engineering and Information Sciences, University of Wollongong, Northfields Avenue, Wollongong, NSW 2522, Australia ${ }^{d}$ Masters Student, School of Civil, Mining and Environmental Engineering, Faculty of Engineering and Information Sciences, University of Wollongong, Northfields Avenue, Wollongong, NSW 2522, Australia
\end{abstract}

\begin{abstract}
A hybrid fibre-reinforced polymer (FRP)-concrete-steel double-skin tubular column (DSTC) consists of an outer FRP tube and an inner steel tube, with the space in between filled with concrete. This paper presents results from the first ever experimental study on hybrid DSTCs with a large rupture strain (LRS) FRP tube, namely, polyethylene terephthalate (PET) FRP tube. The experimental program involved the testing of 12 hybrid DSTC specimens with or without additional concrete inside the inner steel tube. The test results confirmed the ample ductility of hybrid DSTCs with a PET-FRP tube despite the severe local buckling of the inner steel tube at large axial deformations. The test results also suggested that the diameter-to-thickness ratio of the inner steel tube is a more critical parameter in such DSTCs than in DSTCs with a glass, carbon or aramid FRP outer tube.
\end{abstract}

Keywords: Large rupture strain; FRP; steel; concrete; tubular column; confinement, buckling

\section{INTRODUCTION}

Fiber-reinforced polymer (FRP) has emerged as a durable construction material in the past two decades. The unique advantages of FRP composites, including their high strength-to-weight ratio and tailorable mechanical properties, offer ample 
opportunities for innovative novel high-performance structural members. One of the novel structural members incorporating FRP is the hybrid FRP-concrete-steel double-skin tubular column (hybrid DSTC), which was first proposed at The Hong Kong Polytechnic University (PolyU) [1, 2]. A hybrid DSTC consists of an outer tube made of FRP and an inner tube made of steel, with the space in between filled with concrete (Figure 1a). In hybrid DSTCs, the FRP tube is mainly used to provide resistance in the hoop direction, so it can be sacrificed in a fire; the steel tube provides the ductile longitudinal reinforcement needed by the column [2].

A significant number of studies have been conducted on hybrid DSTCs, including those on their compressive behaviour [3-7], flexural behaviour [8,9], and seismic behaviour [10]. The existing studies, however, have generally been limited to the use of an outer tube made of glass FRP (GFRP) [3, 5], carbon FRP (CFRP) [6] or aramid FRP (AFRP) [11]. GFRP, CFRP and AFRP are referred to collectively as conventional FRPs hereafter in this paper. Results from the existing studies show that hybrid DSTCs possess a ductile response as the concrete is well confined by the two tubes (i.e. FRP tube and steel tube) and the outward buckling of steel tube is constrained by the concrete and the FRP tube. The ductile behaviour of hybrid DSTCs ends when the FRP tube ruptures abruptly due to hoop tension, so the ductility of the column depends significantly on the rupture strain of the FRP. It can thus be expected that the ductility and energy absorption capacity of hybrid DSTCs can be further enhanced if an FRP tube with a larger rupture strain is used, leading to columns that are desirable for high seismic regions.

Against this background, this paper presents the first ever experimental study on hybrid DSTCs with a large rupture strain FRP tube. The FRP tubes used in the presented study were made of polyethylene terephthalate FRP (PET-FRP), which is manufactured from waste products such as plastic bottles [12] and possesses a large ruptures train (larger than 7\% according to the manufacturer). The PET-FRP has been demonstrated to be an excellent confining material for seismic retrofit of reinforced concrete columns $[13,14]$. A series of axial compression tests on short hybrid DSTCs were conducted in the present study. For comparison, tests were also conducted on DSTCs with additional concrete infill inside the steel tube, which are referred to as hybrid double-tube concrete columns or hybrid DTCCs (Figure 1b) [15]. When 
conventional FRPs were used, the existing studies (e.g. [3]) showed that, because of the constraint of concrete and FRP, buckling of steel tube in hybrid DSTCs either did not happen or did not have significant effects on the behavior of the column. However, with the use of PET-FRP, the ultimate axial strain of hybrid DSTCs is expected to be very large, which makes severe inward buckling of the steel tube likely to form a significant failure mechanism. This issue was investigated in the present study.

\section{EXPERIMENTAL PROGRAM}

\subsection{Test Specimens}

In total, 12 specimens were prepared and tested under axial compression, including eight DSTC specimens and four DTCC specimens. All specimens had a nominal diameter (i.e. the outer diameter of concrete) of $208 \mathrm{~mm}$ and a height of $500 \mathrm{~mm}$. The DSTC specimens included four pairs of specimens, covering two types of steel tubes (i.e. Types A and B) and three thicknesses of FRP tubes which were composed of two plies, three plies and four plies of PET-FRP, respectively; each pair of specimens were nominally identical. Types A and B steel tubes had the same outer diameter of 139.7 $\mathrm{mm}$, but had thicknesses of $3.5 \mathrm{~mm}$ and $5.4 \mathrm{~mm}$ respectively, leading to two different diameter-to-thickness (D/t) ratios (i.e. 39.9 and 25.9 respectively). The DTCC specimens included two pairs of specimens, covering two types of steel tubes (i.e. Types A and B) and one thickness of FRP tubes which were composed of three plies of PET-FRP; each pair were nominally identical. The details of all specimens are summarized in Table 1. For ease of reference, each specimen is given a name, which starts with four letters to indicate the type of the specimen (i.e. DSTC or DTCC), followed by a letter to indicate the type of the steel tube (i.e. A or B) together with an Arabic numeral to indicate the number of plies of FRP (i.e. 2, 3 or 4); the Roman numeral at the end of some specimen names is used to differentiate two nominally identical specimens. For example, Specimen DSTC-A3-I refers to the first DSTC specimen with a Type-A steel tube and a 3-ply PET-FRP tube.

\subsection{Material Properties}

All specimens were cast in one batch using ready-mix concrete from a local 
manufacturer. Three plain concrete cylinders $(150 \mathrm{~mm} \times 300 \mathrm{~mm})$ were tested to determine the mechanical properties of unconfined concrete, in accordance with AS1012.9 [16]. The elastic modulus, compressive strength and compressive strain at peak stress of the concrete averaged from the cylinder tests were $25.2 \mathrm{GPa}, 28.4 \mathrm{MPa}$ and 0.0025 respectively.

For each type of steel tube, tensile tests of two steel coupons, which were cut from a steel tube along the longitudinal direction, were conducted in accordance with BS 18 [17]. The average values of the elastic modulus, yield stress and tensile strength are summarized in Table 2. In addition, for each type of steel tubes, two hollow steel tubes, which had the same height (i.e. $500 \mathrm{~mm}$ ) as those in the DSTC specimens, were tested under compression. All these steel tubes failed by local buckling that occurred in an elephant's foot mode (Figure 2). The axial load capacities of both steel tubes are also listed in Table 2.

Tensile tests on six coupons were conducted to determine the mechanical properties of the PET-FRP tube according to ASTM-D3039/D3039M [18]. The stress-strain curves obtained from these tests are shown in Figure 3, in which the tensile stresses were calculated based on the nominal thickness of PET-FRP (i.e., $0.819 \mathrm{~mm}$ per ply) provided by the manufacturer. Figure 3 shows that the stress-strain curves are slightly nonlinear with a relatively high slope at small axial strains. The test results also showed that the PET-FRP used in the present study had an average tensile strength of 823.9MPa and an average rupture strain of 0.0956 , which is about 4 times that of glass FRP.

\subsection{Preparation of Specimens}

Polyvinyl chloride (PVC) pipes with an inner diameter of $208 \mathrm{~mm}$ and a height of 500 $\mathrm{mm}$ were used as the outer formwork for the specimens (Figure 4). Before casting concrete, proper measures were taken to ensure that the PVC pipe and the steel tube for each specimen were concentrically located (Figure 4). The PET-FRP tube was formed by a wet-layup process on the surface of hardened concrete, with the fibers oriented in the hoop direction and the overlapping zone being $150 \mathrm{~mm}$ (see Figure 5). 
An additional FRP wrap with a width of $50 \mathrm{~mm}$ was applied at each end of the specimens to avoid premature failure in these regions. The wet-layup process was used as prefabricated PET-FRP tubes were not readily available to the authors. Compared with prefabricated FRP tubes, although the use of the wet-layup process eliminated the possible effect of concrete shrinkage, existing studies [19-21] have shown that such effect is only noticeable when the shrinkage of concrete is relatively large (e.g. when self-compacting concrete is used) and is only limited to the transition region of the typical bilinear stress-strain curve of FRP-confined concrete (i.e. the region connecting the first portion which is similar to that of unconfined concrete and the second portion when the FRP has been effectively activated). It is thus believed that the wet-layup process used in the present study has little effect on the performance of the hybrid column.

\subsection{Test Set-Up and Instrumentation}

For each specimen, four axial strain gauges (V1 to V4 in Figure 5) and four hoop strain gauges (H1 to H4 in Figure 5) with a gauge length of $20 \mathrm{~mm}$ were installed on the outer surface of the FRP tube. These strain gauges were evenly distributed around the circumference at the mid-height of the specimen, with one located at the centre of the overlapping zone (Figure 5). In addition, two axial strain gauges with a gauge length of $10 \mathrm{~mm}$ (i.e. S1 and S2 in Figure 5) were applied at the mid-height (placed $180^{\circ}$ apart from each other) of the steel tube for each specimen. The circumferential layout of the strain gauges is shown in Figure 5.

For each specimen, two linear variable displacement transducers (LVDTs) placed $180^{\circ}$ apart from each other were used to measure the overall axial shortening, while another two LVDTs placed $180^{\circ}$ apart from each other were used to measure the axial deformation of the $150 \mathrm{~mm}$ mid-height region. The layout of these LVDTs and the test set-up are shown in Figure 6. To monitor the buckling process of the inner steel tube in the DSTC specimens, a portable action camera was installed on the bottom surface of the top loading plate (Figure 6).

All the compression tests were conducted at the University of Wollongong using a 500 ton Denison Compression Testing Machine with a displacement control rate of $0.6 \mathrm{~mm}$ 
per minute. In the tests, one steel cap was used at each end of the specimen, with gypsum plaster applied between the cap and the specimen to ensure uniform loading. The axial load was applied directly to both the steel tube and the concrete.

\section{EXPERIMENTAL RESULTS AND DISCUSSIONS}

\subsection{General Behavior}

All DSTC and DTCC specimens failed by hoop rupture of the FRP tube at or close to the mid-height of the specimens (Figures $7 \mathrm{a}$ and $7 \mathrm{~b}$ ) except for Specimen DSTC-A2-II whose test was intentionally terminated before the final failure to examine the deformed shape of the inner steel tube. For the DTCC specimens, the load kept increasing and no significant buckling of the inner steel tube was found after test (Figure 8c). By contrast, the DSTC specimens showed quite different behavior: the inner steel tube experienced significant buckling (Figures 8a and 8b) which led to considerable load reduction during the test; such load reduction, however, could be recovered in the later stage of testing, and at the ultimate state (i.e. FRP rupture) the specimens achieved a higher load than the first peak (Figure 9a). This behavior is clearly different from that of DSTC specimens with a conventional FRP tube $[3,5,6]$, which generally possess a bilinear ascending load-shortening curve, and is mainly due to the extremely large axial shortening that the steel tube in the PET-FRP DSTC specimens experienced. Another test observation associated with the large axial deformation was the partial debonding and local buckling of the PET-FRP tube at the finishing end of the overlapping zone (Figures $7 \mathrm{a}$ and $7 \mathrm{~b}$ ). Nevertheless, such debonding/buckling only happened within a small region at the late stage of tests (i.e. close to the ultimate state), and is believed to have little effect on the overall behavior of the specimens; the final failure was mainly controlled by the rupture of the FRP tube.

\subsection{Axial Load-Shortening Behavior}

The axial load-shortening curves of DSTC specimens with a relatively thin steel tube (i.e. Type-A steel tube) are shown in Figure 9a, where all the curves are terminated at the point of FRP rupture except for Specimen DSTC-A2-II. These curves can generally be divided into three branches (Figure 9a): (1) an approximately bilinear 
ascending branch before the peak load; (2) a gradual descending branch which was caused by inward buckling of the inner steel tube and the associated inward concrete spalling; (3) another ascending branch where the axial load increased approximately linearly with the axial shortening until the final failure by rupture of the FRP tube. It should be noted that the test of Specimen DSTC-A2-II was terminated early and its curve thus only included the first two branches. It is evident that the curves shown in Figure 9a are significantly different from the axial load-shortening curves of DSTCs with a conventional FRP tube $[3,5,6]$ which typically had an approximately bilinear shape (i.e. similar to the first branch of the curves shown in Figures 9a). This is not surprising as the rupture of FRP usually occurs before the first peak if conventional FRPs, which have a much smaller rupture strain than PET-FRP, are used to fabricate the outer tube.

Figure $9 \mathrm{~b}$ shows the axial load-shortening curves of the two DSTC specimens with a Type-B steel tube (i.e. Specimens DSTC-B3-I, II). Figure 9b shows that the curves of Specimens DSTC-B3-I, II may also be divided into three branches in the same way as discussed above for the DSTC specimens with a Type-A steel tube (Figure 9a). However, the load decrease in the second branch and the load increase in the third branch were both much less pronounced when a thicker steel tube (i.e. Type-B steel tube) was used; the second and third branches of Specimens DSTC-B3-I, II may thus also be seen as a single branch with an approximately constant load.

The axial load-shortening curves of the DTCC specimens are plotted and compared with those of the corresponding DSTC specimens in Figure 10. It is evident that the DTCC specimens all had a bilinear axial load-shortening curve which is similar to those of FRP-confined solid concrete columns [2]. Because of the additional concrete inside the inner steel tube, the curves of the DTCC specimens show significantly higher loads than the curves of the corresponding DSTC specimens, and the difference increases with axial shortening due to significant buckling of steel tube in the latter at large axial deformations. The ultimate axial shortening of the two types of specimens (i.e. DTCC and DSTC specimens) is, however, comparable.

The key test results of all specimens are summarized in Table 3. In this table, $P u$ and $S_{u}$ are the axial load and shortening at the point of FRP rupture, respectively. For 
DSTC specimens, the axial load $(P)$ and shortening $(S)$ at the following characteristic points are also summarized in Table 3: (1) $P_{f}$ and $S_{f}$ for the first peak point on the load-shortening curves (i.e., point B in Figure 11a); (2) $P_{t}$ and $S_{t}$ for the trough point of the load-shortening curves (i.e., point $\mathrm{C}$ in Figure 11a).

\subsection{Buckling Behavior of Inner Steel Tube}

The inner steel tubes in the DSTC specimens experienced significant local buckling due to the extremely large axial shortening they were subjected to, as well as the lack of internal support (Figure 8). To further examine the buckling process, the deformed shapes of the inner steel tube at different stages of loading, as recorded by the action camera (see Figure 6), are shown in Figure 11b for a typical specimen (i.e. Specimen DSTC-A3-II). The four subfigures in Figure 11b are corresponding to four points on the load-shortening curve shown in Figure 11a, respectively. According to Figure 11, the buckling process of the inner steel tube can be described as follows: (1) no apparent bucking occurred before the first peak (i.e. Point B) was reached, as evident from the deformed shape of the steel tube at Point A when the axial load was $98 \%$ that of Point B; (2) at Point B, a slight wrinkle was noticed near the mid-height (Figure 11b-B); (3) the first wrinkle developed with the decease of load, and new wrinkles appeared at various circumferential locations close to the mid-height of the tube (the numbers in Figure 11b indicate the order in which the wrinkles occurred); the wrinkles became quite significant at the trough point of the load-shortening curve (i.e. Point C, see Figure 11b-C); (5) after Point C, no new wrinkles were formed, but the existing wrinkles kept progressing with an increasing load until the rupture of the FRP tube (see Figures 11b-D). The steel tube was taken out from the specimen after test and its outer surface was shown in Figure 8a. The locations of the wrinkles were found to be quite diverse in DSTC specimens and some of them were outside the 150 mm mid-height region.

The buckling of steel tube significantly affected its local deformation. To illustrate this effect, the readings of the two axial strain gauges attached at the mid-height of the steel tube (i.e. S1 and S2, see Figure 5) in Specimen DSTC-A3-II are plotted together with the axial load-shortening curve in Figure 11a. Hereafter in this paper, compressive stresses and strains are defined to be positive while tensile stresses and 
strains are defined to be negative, unless otherwise specified. It is evident that the two readings increased with the axial shortening before the first peak load was reached. After that, the strain gauge readings started to decrease with the axial shortening. Further examination after test revealed that both strain gauges did not cross the first buckling wrinkle. The decrease of their readings was a result of partial unloading of the steel tube, while part of the load taken by the steel tube was shifted to the adjacent concrete infill. The development of strain gauge readings clearly indicates the beginning of local buckling of the steel tube, which is consistent with the observation from the images recorded by the action camera (Figure 11b).

The axial shortenings corresponding to the initiation of buckling of steel tubes (referred to as buckling shortening hereafter) are summarized in Table 4 for all the DSTC specimens as well as the bare steel tubes tested under axial compression. For DSTC specimens, the buckling is assumed to have occurred at the first peak load. This assumption is reasonably consistent with observations from the videos recorded by the action camera as well as the readings of axial strain gauges on the steel tubes, as discussed above, although the buckling might have initiated slightly earlier. In Table $4, S_{B}$ is the buckling shortening of bare steel tubes while $S_{D}$ is the buckling shortening of steel tubes in DSTC specimens. It is evident from Table 4 that the buckling of steel tube was significantly delayed in DSTC specimens because of the constraint of concrete. The $S_{D} / S_{B}$ ratio is shown to increase with the thickness of the FRP tube, and is up to 2.55 for four-ply specimens.

\subsection{Effect of Thickness of FRP Tube}

Existing studies (e.g. [3]) have shown conclusively that the behavior of DSTCs depends on the amount of confining FRP. When all other parameters are the same, a thicker FRP tube leads to greater increases in strength and ductility. The existing studies, however, have been limited to the use of a conventional FRP tube, and thus have shed little insight on how the thickness of FRP tube affects the behavior of DSTCs with significant buckling of the inner steel tube. This effect can be examined using the test results in the present study as presented in Figure 9a and Table 3. It is evident from Figure 9a and Table 3 that a thicker FRP tube generally leads to a larger first peak load and the corresponding shortening (i.e. $P_{f}$ and $S_{f}$ ), a larger load at the 
trough point of the load-shortening curve (i.e. $P_{t}$ ), as well as a larger load and shortening at the rupture of FRP tube (i.e. $P u$ and $S_{u}$ ). The only exception appears to be Specimen DSTC-A3-II which had a relatively small ultimate axial shortening probably due to the relatively small rupture strain of FRP in this specimen. By contrast, the thickness of FRP tube appeared to have little effect on the axial shortening at the trough point of the load-shortening curve (i.e. $S_{t}$ ). It is also evident that the $P_{t} / P_{f}$ ratio increases with the thickness of FRP tube due to its confinement to the concrete.

Figure 12 shows the nominal axial strain-hoop strain curves of the DSTC specimens with Type A steel tubes. The nominal axial strains were taken as the average strains over the whole height of the specimen based on the average overall axial shortening. The nominal axial strains were used instead of readings from the axial strain gauges attached at the mid-height as the latter was significantly affected by the localized deformation of the columns especially after the buckling of the inner steel tube. The hoop strains shown in Figure 12 were averaged from readings of the three hoop strain gauges outside the overlapping zone, expect for Specimens DSTC-A2-II. For this specimen, one of the three hoop strain gauges was damaged during the tests, so the hoop strains plotted in Figure 12 were the average of the remaining two strain gauges. Surprisingly, the effect of thickness of FRP is shown to be unclear from Figure 12. This is different from the well-known observation for FRP-confined concrete columns that, at the same axial strain, concrete confined by a thicker FRP tube typically has a lower lateral strain. The unexpected results shown in Figure 12 are believed to be at least due to the following reasons: (1) buckling of steel tube, which was quite localized and had led to non-uniform lateral deformation of concrete; the locations of such highly localized deformation were different in different specimens and could have affected readings of the hoop strain gauges located at discrete points (see Figure 5); (2) the hoop strain gauges were attached at the outer surface of the FRP tube and their readings might have been affected by the bending of the FRP tube given that its actual thickness (e.g. around $10 \mathrm{~mm}$ for 4-ply specimens) was considerably larger than conventional FRP wraps. 


\subsection{Effect of Thickness of Steel Tube}

\section{DSTC Specimens}

Figure 13 compares the axial load-shortening curves of two pairs of DSTC specimens (i.e. DSTC-A3-I, II and DSTC-B3-I, II), of which the only difference was the thickness of inner steel tube. It is evident that, because of the use of a thicker steel tube, the curves of Specimens DSTC-B3-I, II are always higher than those of Specimens DSTC-A3-I, II, and terminate at a larger ultimate load. Table 3 also shows that the values of $P_{f}, S_{f}, P_{t}, S_{t}$ and $P_{u}$ of the former are larger than the latter. By contrast, the ultimate axial shortenings of Specimens DSTC-B3-I, II are shown to be generally smaller than those of Specimens DSTC-A3-I, II (Table 3 and Figure 13).

The nominal axial strain-hoop strain curves of Specimens DSTC-A3-I, II and DSTC-B3-I, II are compared in Figure 14, where the hoop strains were averaged from the three strain gauges outside the overlapping zone except for Specimens DSTC-B3-II. For this specimen, the hoop strains were the average of two strain gauge readings as the other one damaged during the test. It is evident that the shapes of the two pairs of curves are different: (1) for the DSTC-A3 pair, both curves are approximately linear at the beginning and then become significantly nonlinear with a decreasing rate of hoop strain increase, despite the considerable difference between the two nominally identical specimens; (2) for the DSTC-B3 pair, the two curves are close to each other and are only slightly nonlinear until the ultimate state. The difference in the shape of curves is believed to be at least partially due to the use of different steel tubes: the steel tubes in the DSTC-A3 pair had a larger D/t ratio and experienced more severe buckling during the tests, so that in the later stage of loading, the tendency of inward movement of concrete was more pronounced than that in the DSTC-B3 pair which had a thicker steel tube; as a result, the rate of outward expansion of concrete, as recorded by the hoop strain gauges, was reduced in the later stage of the DSTC-A3 pair. The above also explains the relatively large ultimate axial shortening of the DSTC-A3 pair.

\section{$\underline{\text { DTCC Specimens }}$}

Figure 15 compares the axial load-shortening curves of two pairs of DTCC specimens (i.e. DTCC-A3-I, II and DTCC-B3-I, II), of which the only difference was the 
thickness of inner steel tube. It is evident that the curves of the DTCC-B3 pair are consistently higher than the DTCC-A3 pair, and terminate at larger ultimate loads $(P u)$ and ultimate axial shortenings $\left(S_{u}\right)$ (see also Table 3). This is because of the use of a thicker steel tube in the former specimens. Figure 16 shows the nominal axial strain-hoop strain curves of the two pairs of specimens expect Specimen DTCC-B3-I whose hoop strain data was accidently lost due to a mistake during the test. The hoop strains were averaged from the three strain gauges outside the overlapping zone. It is evident from Figure 16 that there is no significant difference between the three curves, suggesting that the effect of thickness of steel tube on the lateral expansion behavior is negligible. However, it is worth noting that the rupture strain of Specimen DTCC-B3-II is considerably higher than those of Specimens DTCC-A3-I, II, although the FRP tube in the three specimens were nominally identical. Further examination shows that the hoop strain distributions in Specimens DTCC-A3-I, II were more non-uniform than that in Specimen DTCC-B3-II, leading to smaller average hoop strains at the rupture of FRP tube. This might be due to the use of a thinner steel tube in the DTCC-A3 pair, although solid conclusions can only be made when more test data is available.

\section{CONCLUSIONS}

This paper has presented an experimental study on the axial compressive behavior of hybrid DSTCs with a large rupture strain FRP tube (i.e. PET-FRP tube). The test variables included the section configuration as well as the thicknesses of the FRP tube and the steel tube. The results and discussions presented in the paper allow the following conclusions to be drawn:

(1) Hybrid DSTCs with a PET-FRP tube process extremely good ductility: the specimens tested in the present study had an ultimate axial strain of up to around 0.17 ;

(2) Severe buckling of the steel tube occurred in PET-FRP DSTCs before the rupture of FRP tube, due to the large rupture strain of PET-FRP;

(3) The axial load-shortening curves of PET-FRP DSTCs can generally be divided into three branches: a bilinear ascending branch, a gradual descending branch and a linear ascending branch;

(4) The behaviors of PET-FRP DSTCs, in particular the second and third branches of 
load-shortening curves, depend significantly on the $\mathrm{D} / \mathrm{t}$ ratio of the steel inner tube; the load decrease in the second branch and the load increase in the third branch both increase with the $\mathrm{D} / \mathrm{t}$ ratio;

(5) Similar to conventional FRPs, a thicker PET-FRP tube generally leads to higher ultimate load and larger ultimate axial deformation of the hybrid DSTCs;

(6) The behavior of PET-FRP DSTCs with additional concrete inside the steel tube (i.e. DTCCs) is significantly different from those without additional concrete infill: the DTCC specimens generally have a bilinear axial load-shortening curve and the effect of $\mathrm{D} / \mathrm{t}$ ratio of steel tube in DTCC specimens is less pronounced than in DSTC specimens.

In the hybrid DSTCs, the steel tube is under combined axial compression and lateral pressure, and its buckling is further complicated by the complex stress state of the surrounding concrete which is subjected to a large deformation. Future studies using a sophisticated finite element (FE) model are needed to further investigate the buckling behavior of the steel tube and the load carrying mechanism in the hybrid column. Such a FE model should involve the use of a reliable three-dimensional constitutive model for the concrete, with due consideration of the unique features of FRP-confined concrete, and should be verified with the test results in various terms.

\section{ACKNOWLEDGEMENTS}

The authors are grateful for the financial supports received from the Australian Research Council through a Discovery Early Career Researcher Award (Project ID: DE140101349) for the first author. The authors also wish to thank Messrs Nick Field and Jordan Hargraves for their valuable contribution to the experimental work.

\section{REFERENCES}

[1] Teng JG, Yu T, Wong YL. Behaviour of hybrid FRP-concrete-steel double-skin tubular columns, In: Proceedings, the Second International Conference on FRP Composites in Civil Engineering, December 8-10 2004, Adelaide, Australia; 811-818.

[2] Teng JG, Yu T, Wong YL, Dong SL. Hybrid FRP-concrete-steel tubular columns: concept and behavior. Construction and Building Materials 2007; 21: 846-54.

[3] Wong YL, Yu T, Teng JG, Dong SL. Behavior of FRP-confined concrete in annular section columns. Composites Part B: Engineering 2008; 39: 451-66. 
[4] Yu T, Wong YL, Teng JG. Behavior of hybrid FRP-concrete-steel double-skin tubular columns subjected to eccentric compression, Advances in Structural Engineering 2010; 13: 961-74.

[5] Yu T, Teng JG. Behavior of hybrid FRP-concrete-steel double-skin tubular columns with a square outer tube and a circular inner tube subjected to axial compression, Journal of Composites for Construction 2013; 17: 271-79.

[6] Ozbakkaloglu T, Fanggi BL. Axial compressive behavior of FRP-concrete-steel double-skin tubular columns made of normal-and high-strength concrete. Journal of Composites for Construction 2014; 18: 04013027.

[7] Ozbakkaloglu T, Fanggi BAL. FRP-HSC-steel composite columns: behavior under monotonic and cyclic axial compression. Materials and Structures 2015; 48: 1075-93.

[8] Yu T, Wong YL, Teng JG, Dong SL, Lam SS. Flexural behaviour of hybrid FRP-concrete-steel double skin tubular members, Journal of Composites for Construction 2006; 10: 443-52.

[9] Zhao JL, Teng JG, Yu T, Li LJ. Behavior of large-scale hybrid FRP-concrete-steel double-skin tubular beams with shear connectors, Journal of Composites for Construction 2015; 10: 04016015.

[10] Zhang B, Teng JG, Yu T. Experimental behaviour of hybrid FRP-concrete-steel double-skin tubular columns under combined axial compression and cyclic lateral loading, Engineering Structures 2015; 99: 214-31.

[11] Fanggi BAL, Ozbakkaloglu T. Compressive behavior of aramid FRP-HSC-steel double-skin tubular columns. Construction and Building Materials 2013; 48: 554-65.

[12] Lechat C, Bunsell AR, Davies P. Tensile and creep behaviour of polyethylene terephthalate and polyethylene naphthalate fibres. Journal of Materials Science 2011; 46: 528-33.

[13] Dai JG, Bai YL, Teng JG. Behavior and modeling of concrete confined with FRP composites of large deformability. Journal of Composites for Construction 2011; 15: 963-73.

[14] Dai JG, Lam L, Ueda T. Seismic retrofit of square RC columns with polyethylene terephthalate (PET) fibre reinforced polymer composites. Construction and Building Materials 2012; 27: 206-17.

[15] Teng JG, Yu T. Innovative combination of FRP, steel and concrete to achieve high-performance structures, In: Proceedings of Second International Conference on Sustainable Urbanization, 7-9 January, Hong Kong, China; 2015.

[16] AS1012.9. Method of testing concrete: Compressive strength tests- concrete, mortar and grout specimens. Standards Australia; 2014.

[17] BS18. Method for tensile testing of metals (including aerospace materials), British Standards Institution; 1987.

[18] ASTM-D3039/D3039M. Standard test method for tensile properties of polymer matrix composite materials. American Society for Testing and Materials, Philadelphia, USA;2014.

[19] Shahawy M, Mirmiran A, Beitelman T. Tests and modeling of carbon-wrapped concrete columns. Composites Part B: Engineering 2000; 31: 471-80.

[20] Zhang, B., Yu, T. and Teng, J.G. Behaviour of concrete-filled FRP tubes under 
cyclic-axial compression. Journal of Composites for Construction 2014, 10.1061/(ASCE)CC.1943-5614.0000523, 04014060.

[21] El-Chabib, H., Nehdi, M. and El-Naggar, M.H. Behavior of SCC confined in short GFRP tubes. Cement \& Concrete Composites 2005, 27: 55-64. 
Table 1. Details of specimens

\begin{tabular}{lcccc}
\hline & $\begin{array}{c}\text { Number } \\
\text { of plies } \\
\text { of FRP }\end{array}$ & $\begin{array}{c}\text { Outer diameter } \\
\text { of steel tube }\end{array}$ & $\begin{array}{c}\text { Thickness } \\
\text { of steel } \\
\text { tube }(\mathrm{t})\end{array}$ & $\begin{array}{c}\text { D/t ratio } \\
\text { of steel } \\
\text { tube }\end{array}$ \\
& 2 & 139.7 & 3.5 & 39.9 \\
\hline DSTC-A2-I, II & 3 & 139.7 & 3.5 & 39.9 \\
DSTC-A3-I, II & 4 & 139.7 & 3.5 & 39.9 \\
DSTC-A4-I, II & 3 & 139.7 & 5.4 & 25.9 \\
DSTC-B3-I, II & & & & \\
& 3 & 139.7 & 3.5 & 39.9 \\
DTCC-A3-I, II & 3 & 139.7 & 5.4 & 25.9 \\
\hline DTCC-B3-I, II & 3 & &
\end{tabular}


Table 2. Mechanical properties of steel tubes

\begin{tabular}{ccccc}
\hline & Yield & & Axial load capacity \\
Steel tube & $\begin{array}{c}\text { Elastic modulus } \\
(\mathrm{GPa})\end{array}$ & $\begin{array}{c}\text { stress } \\
(\mathrm{MPa})\end{array}$ & $(\mathrm{MPa})$ & $(\mathrm{kN})$ \\
\hline Type A & 193 & 325 & 470 & 561 \\
Type B & 194 & 270 & 360 & 747 \\
\hline
\end{tabular}


Table 3. Key test results

\begin{tabular}{|c|c|c|c|c|c|c|c|c|c|c|c|c|c|}
\hline Specimens No. & $\begin{array}{c}\boldsymbol{P}_{f} \\
(k N)\end{array}$ & $\begin{array}{c}\text { Average } \\
\boldsymbol{P}_{f}\end{array}$ & $\begin{array}{c}\boldsymbol{S}_{f} \\
(\mathrm{~mm})\end{array}$ & $\begin{array}{c}\text { Average } \\
S_{f}\end{array}$ & $\begin{array}{c}\boldsymbol{P}_{\boldsymbol{t}} \\
(k N)\end{array}$ & $\begin{array}{c}\text { Average } \\
\boldsymbol{P}_{\boldsymbol{t}}\end{array}$ & $\begin{array}{c}\boldsymbol{S}_{\boldsymbol{t}} \\
(\mathrm{mm})\end{array}$ & $\begin{array}{c}\text { Average } \\
\boldsymbol{S}_{\boldsymbol{t}}\end{array}$ & $\begin{array}{c}P_{t} / P_{f} \\
(\%)\end{array}$ & $\begin{array}{c}\boldsymbol{P}_{\boldsymbol{u}} \\
(k N)\end{array}$ & $\begin{array}{c}\text { Average } \\
\boldsymbol{P}_{u}\end{array}$ & $\begin{array}{c}\boldsymbol{S}_{\boldsymbol{u}} \\
(\mathrm{mm})\end{array}$ & $\begin{array}{c}\text { Average } \\
\boldsymbol{S}_{\boldsymbol{u}}\end{array}$ \\
\hline DSTC-A2-I & 1268 & 1287 & 13.8 & 14.7 & 1002 & 1040 & 29.2 & 31.4 & 80.8 & 1403 & $1403^{*}$ & 72.2 & $72.2^{*}$ \\
\hline DSTC-A2-II & 1305 & & 15.5 & & 1077 & & 33.6 & & & N/A & & N/A & \\
\hline DSTC-A3-I & 1424 & 1503 & 14.9 & 16.6 & 1205 & 1258 & 34.3 & 32.6 & 83.7 & 1522 & 1601 & 78.6 & 71.6 \\
\hline DSTC-A3-II & 1581 & & 18.2 & & 1311 & & 30.9 & & & 1650 & & 64.5 & \\
\hline DSTC-A4-I & 1658 & 1643 & 19.8 & 18.6 & 1460 & 1465 & 32.1 & 31.1 & 89.2 & 2179 & 2091 & 83.9 & 84.7 \\
\hline DSTC-A4-II & 1627 & & 17.3 & & 1470 & & 30.0 & & & 2002 & & 85.4 & \\
\hline DSTC-B3-I & 1755 & 1826 & 31.2 & 30.8 & 1690 & 1772 & 47.7 & 46.7 & 97.0 & 1717 & 1821 & 51.7 & 57.3 \\
\hline DSTC-B3-II & 1897 & & 30.3 & & 1853 & & 45.6 & & & 1925 & & 62.9 & \\
\hline DTCC-A3-I & - & - & - & - & - & - & - & - & - & 3371 & 3336 & 59.7 & 58.7 \\
\hline DTCC-A3-II & - & - & - & - & - & - & - & - & - & 3301 & & 57.6 & \\
\hline DTCC-B3-I & - & - & - & - & - & - & - & - & - & 3770 & 3794 & 69.0 & 67.9 \\
\hline DTCC-B3-II & - & - & - & - & - & - & - & - & - & 3817 & & 66.8 & \\
\hline
\end{tabular}

${ }^{*}$ Based on the results from a single specimen. 
Table 4. Buckling shortening of steel tube in DSTCs

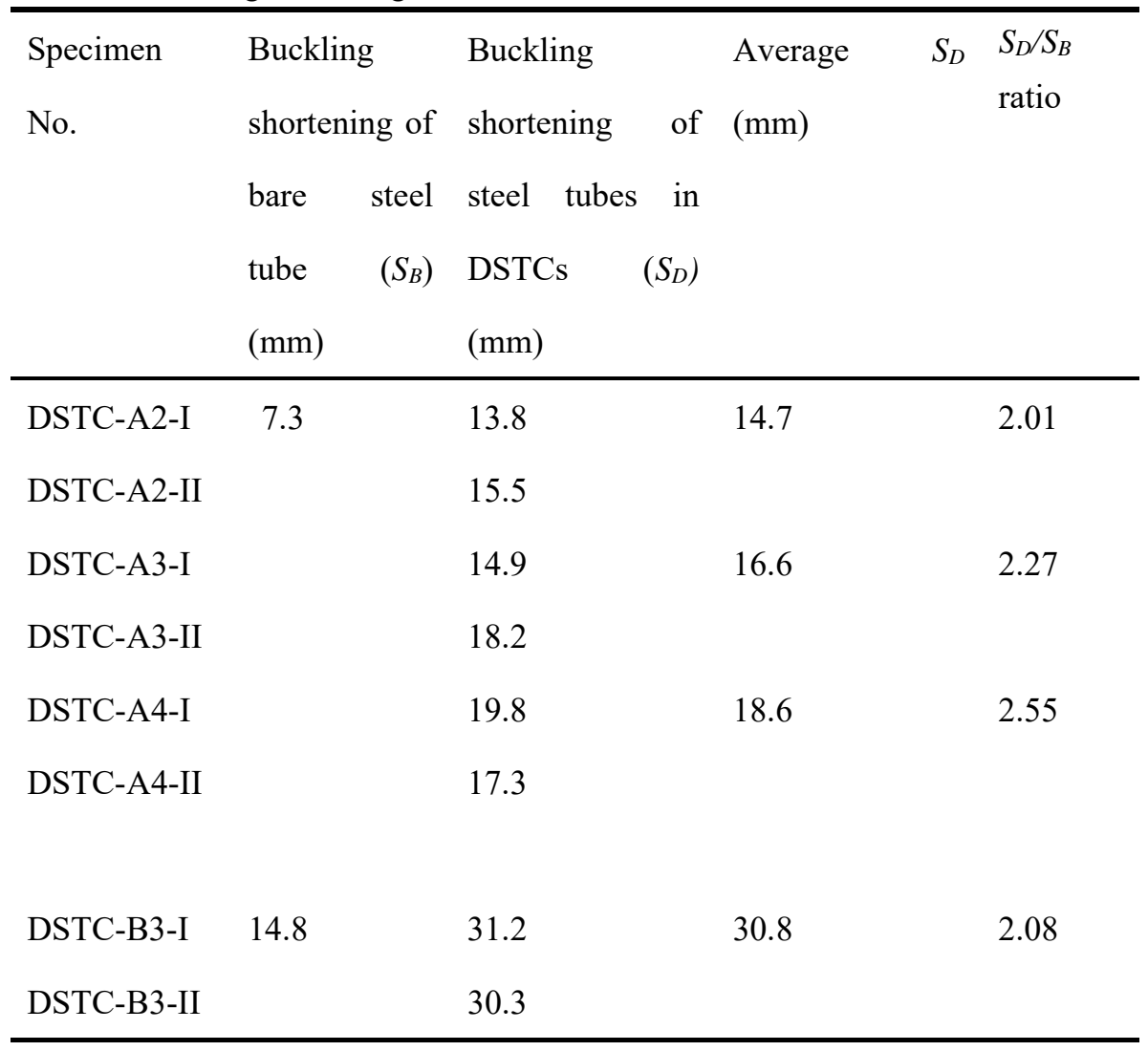




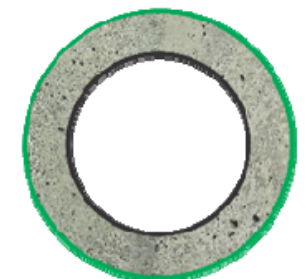

(a)

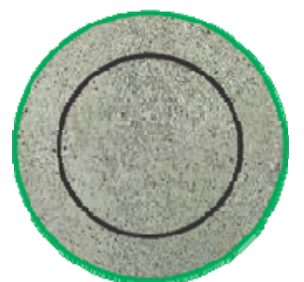

(b)

PET-FRP $\square$ Steel tube 재 Concrete

Fig. 1 Cross-sections of specimens:

(a) DSTCs and (b) DTCCs

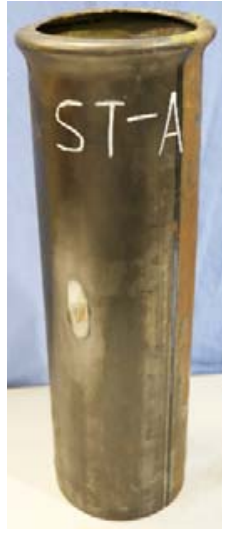

(a)

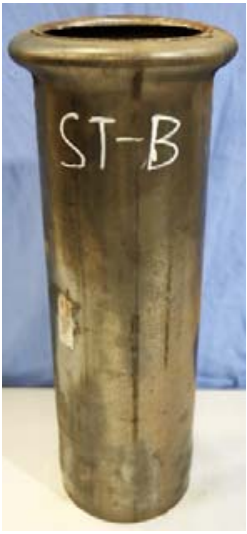

(b)

Fig. 2 Buckling mode of steel tubes:

(a) Type A, and (b) Type B

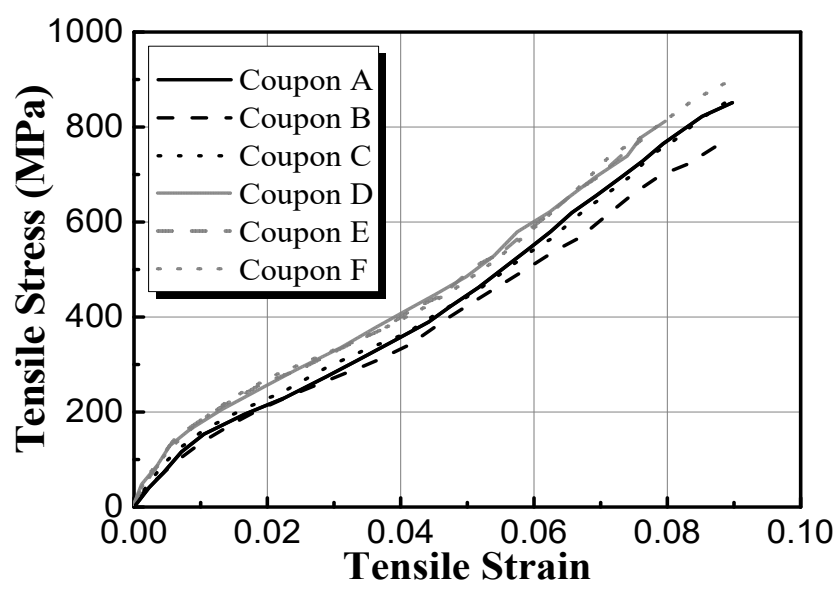

Fig. 3 Tensile stress-strain curves of PET-FRP coupons 


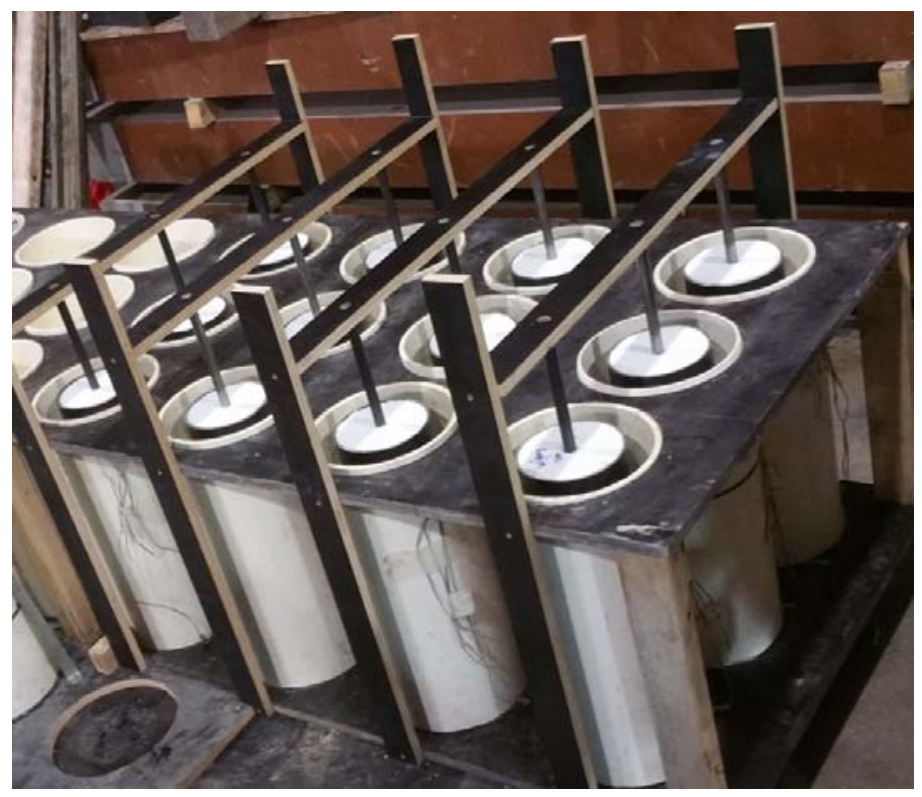

Fig. 4 Formwork for casting concrete

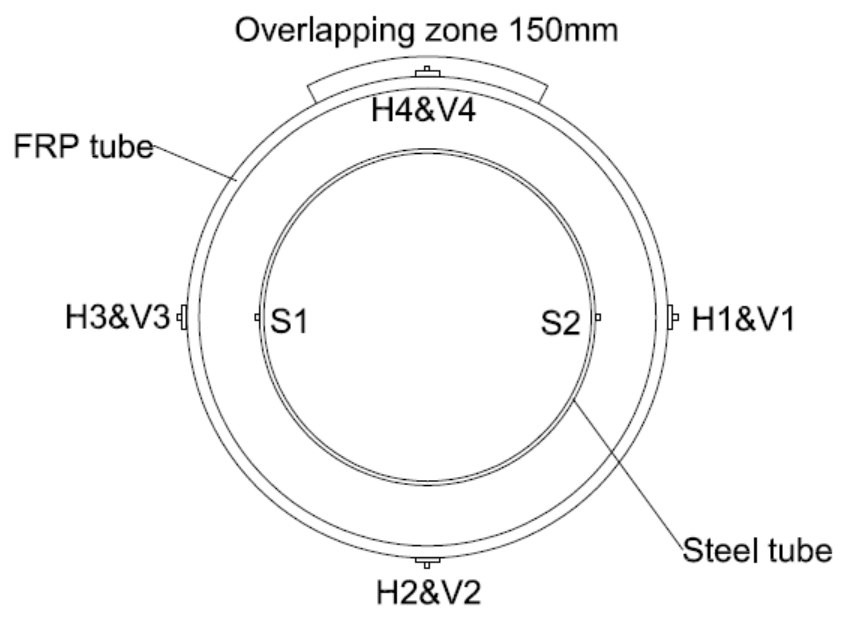

Fig. 5 Layout of strain gauges 


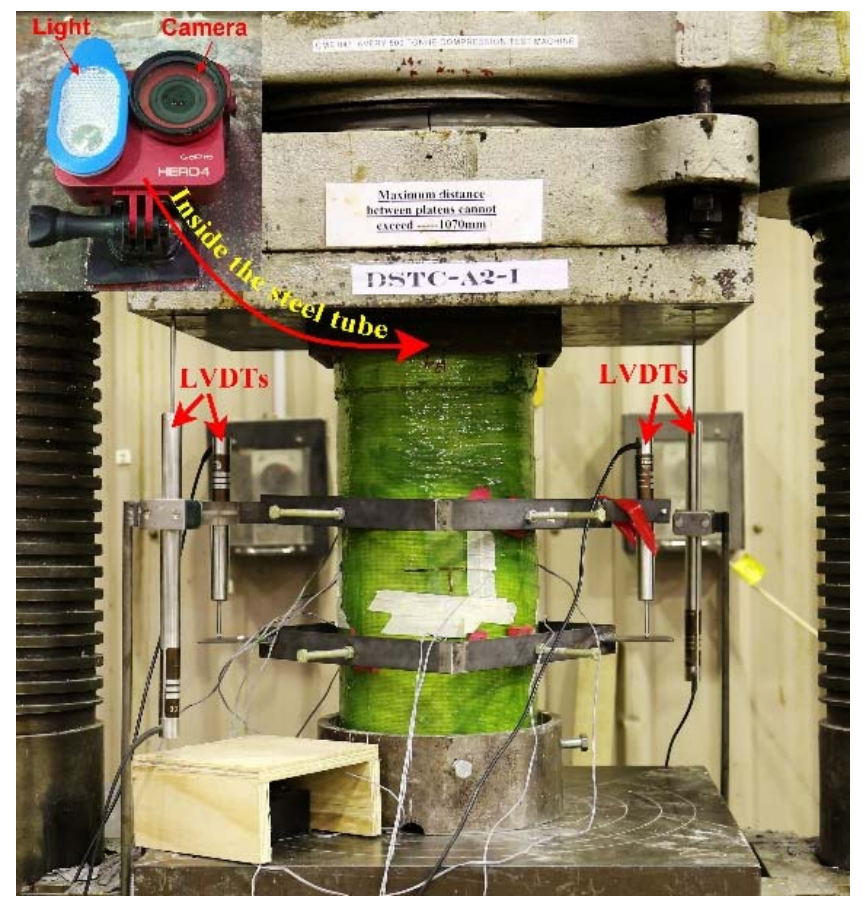

Fig. 6 Test set-up

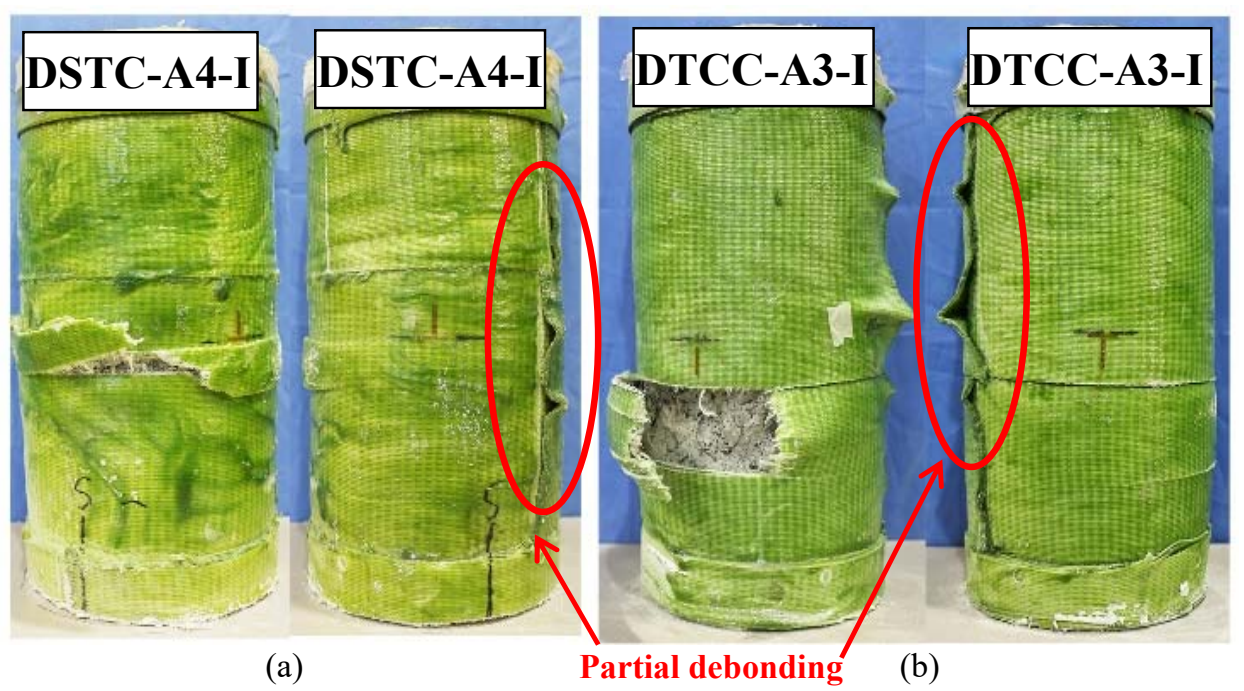

Figure.7 Typical failure modes of specimens:

(a) DSTC-A4-I and (b) DTCC-A3-I 


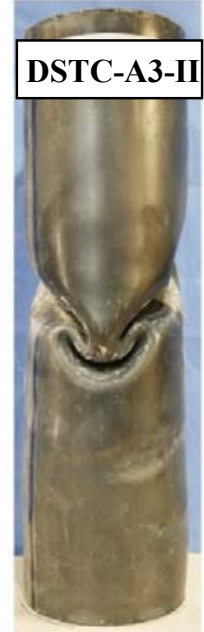

(a)

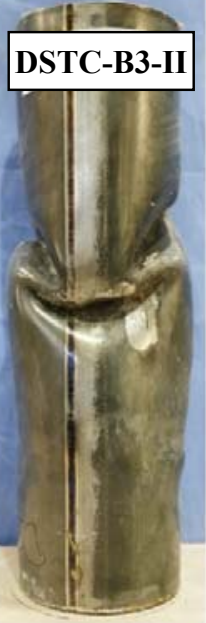

(b)

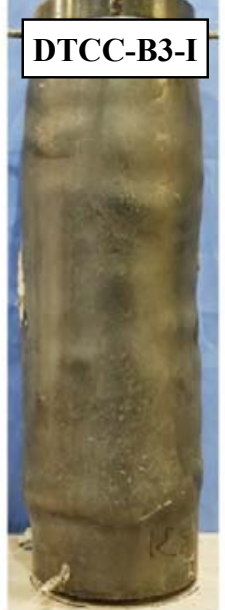

(c)

Fig.8 Buckling of steel tube in

(a) DSTC-A3-II; (b) DSTC-B3-II; and (c) DTCC-B3-II 


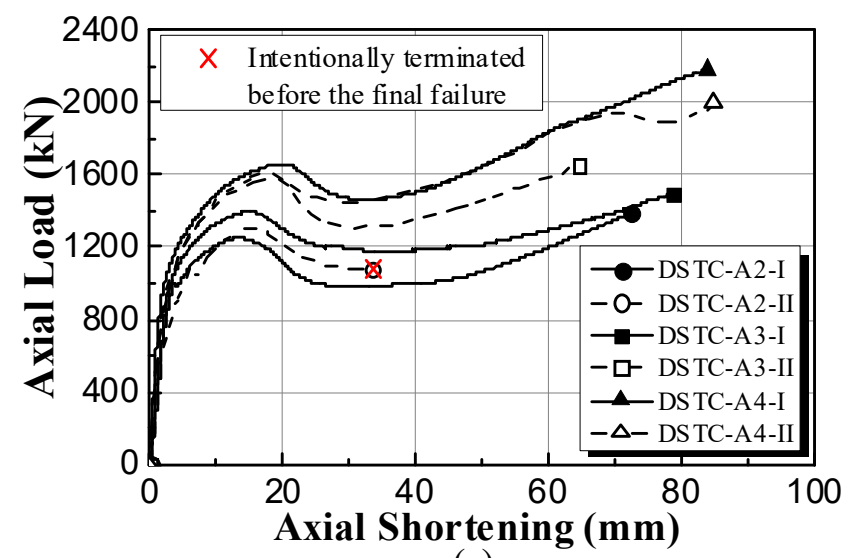

(a)

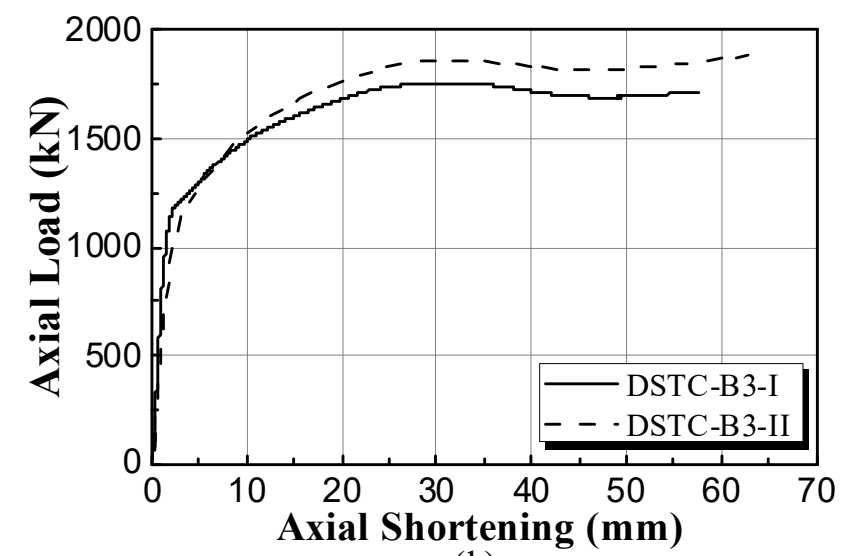

(b)

Fig. 9 Axial load-axial strain curves of

(a) DSTCs with Type A steel tube; and (b) DSTCs with Type B steel tube

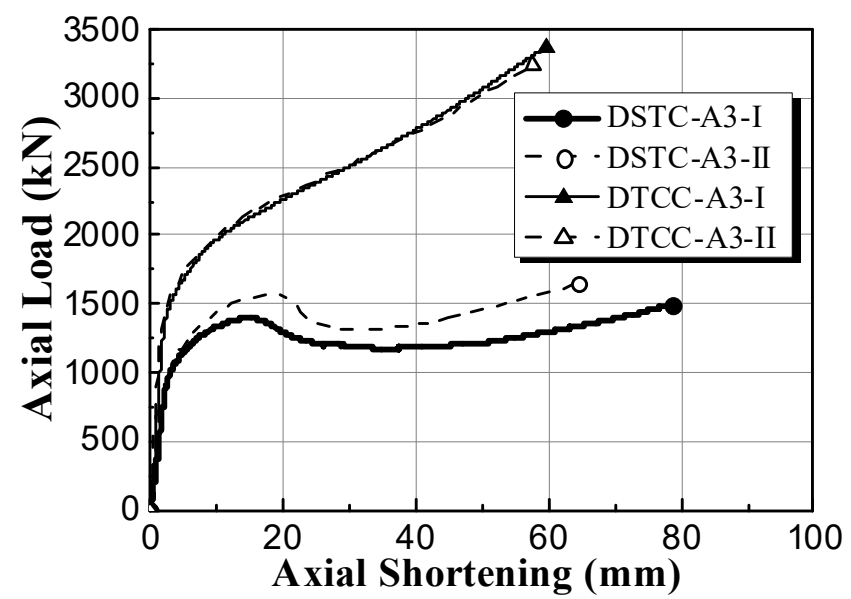

Fig. 10 Comparison between DSTCs and DTCCs 


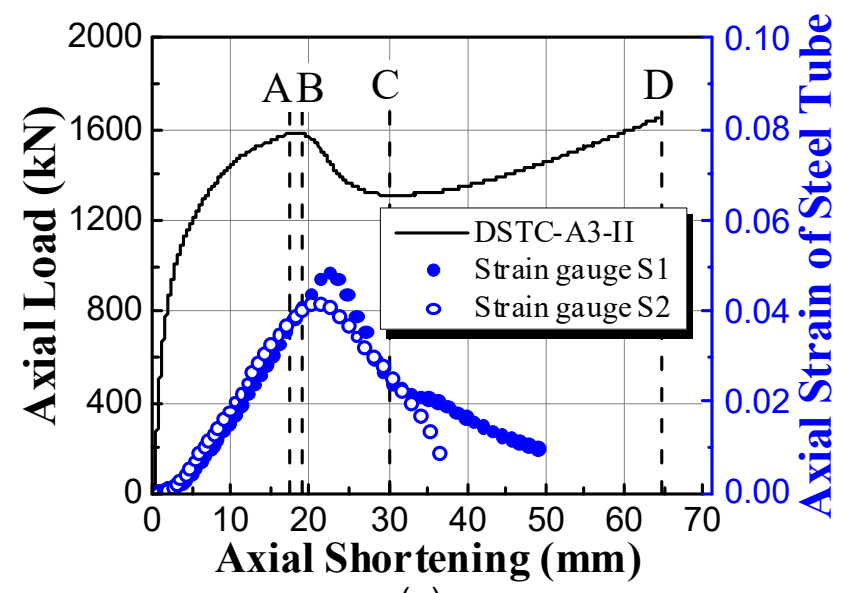

(a)

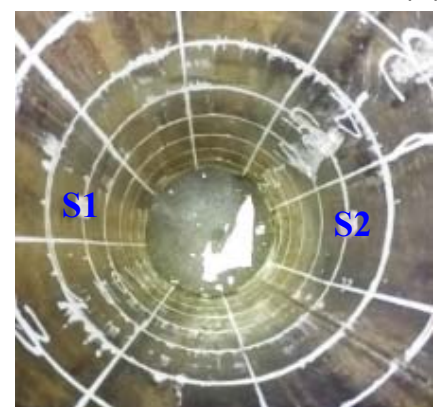

A

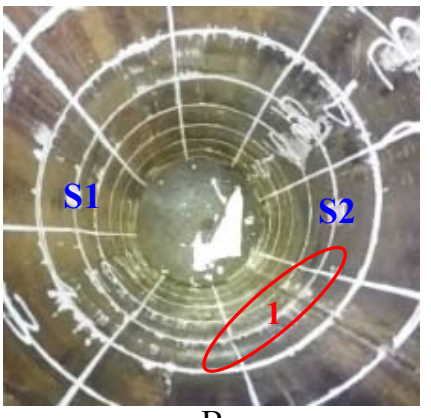

B

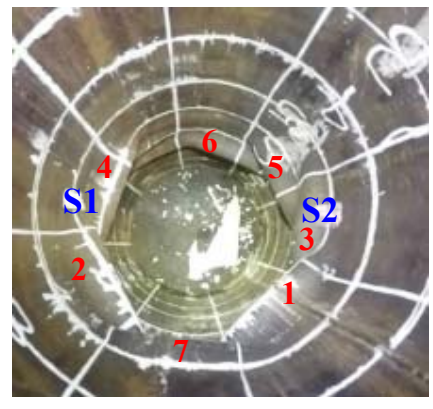

$\mathrm{C}$

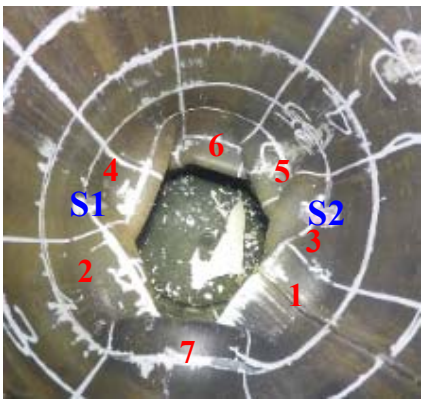

$\mathrm{D}$

(b)

Fig. 11 Buckling process of steel tube in DSTC-A3-II:

(a) Axial load-shortening curve and axial strain gauge readings; and (b) deformed shapes of steel tube

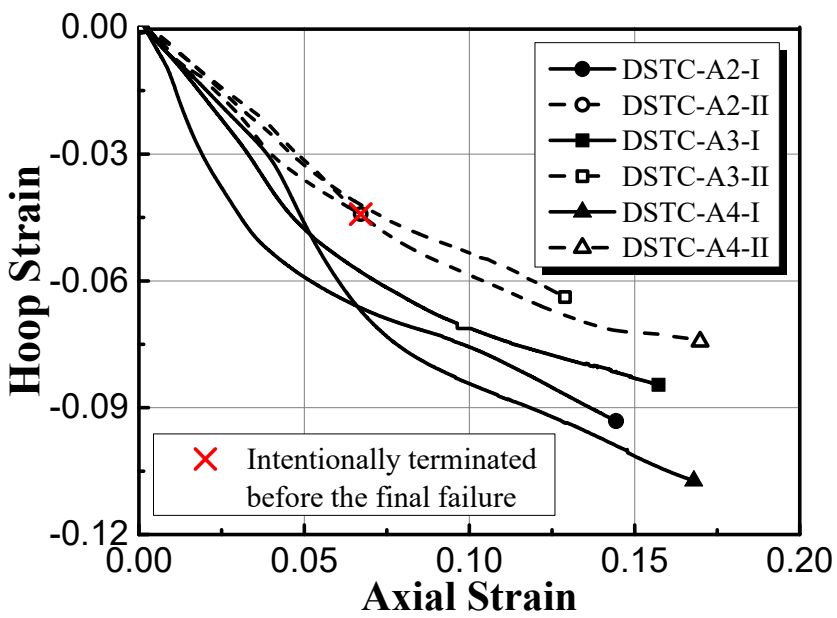

Fig. 12 Axial-hoop strain curves of DSTCs with Type A steel tube 


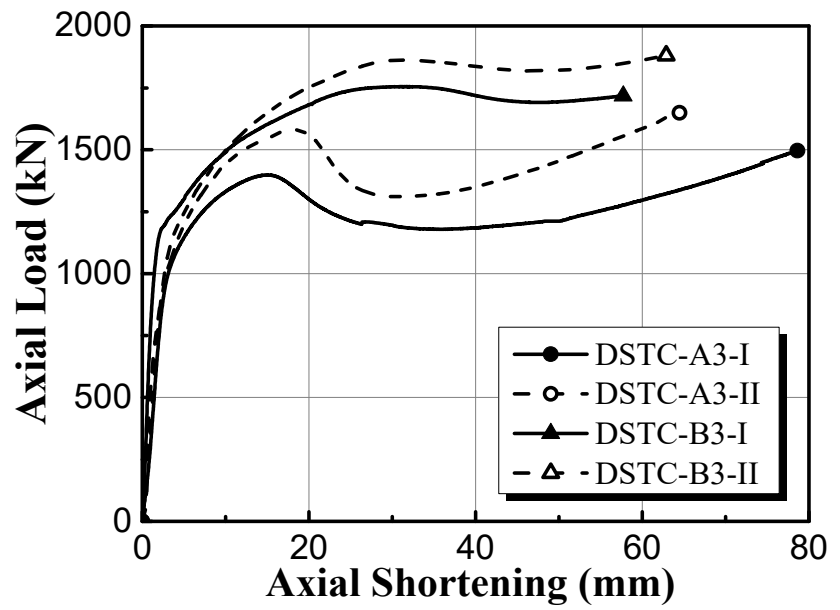

Fig. 13 Effect of steel tube on axial load-shortening behavior of DSTCs

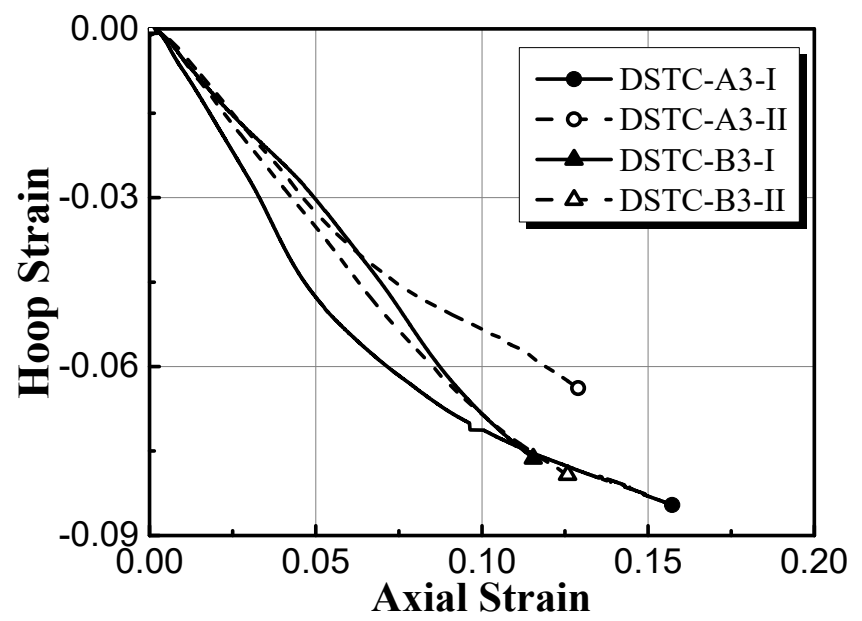

Fig. 14 Effect of steel tube on lateral expansion behavior of DSTCs

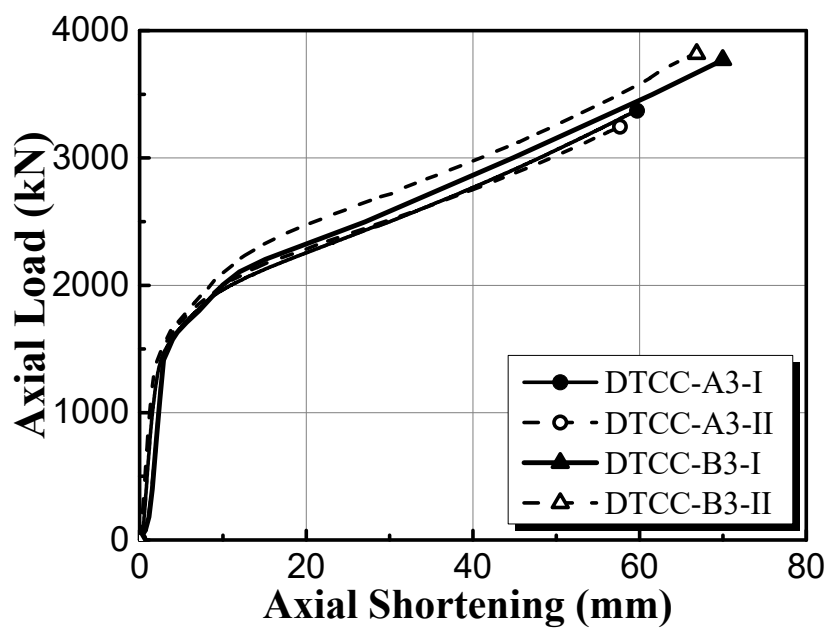

Fig. 15 Effect of steel tube on axial load-shortening behavior of DTCCs 


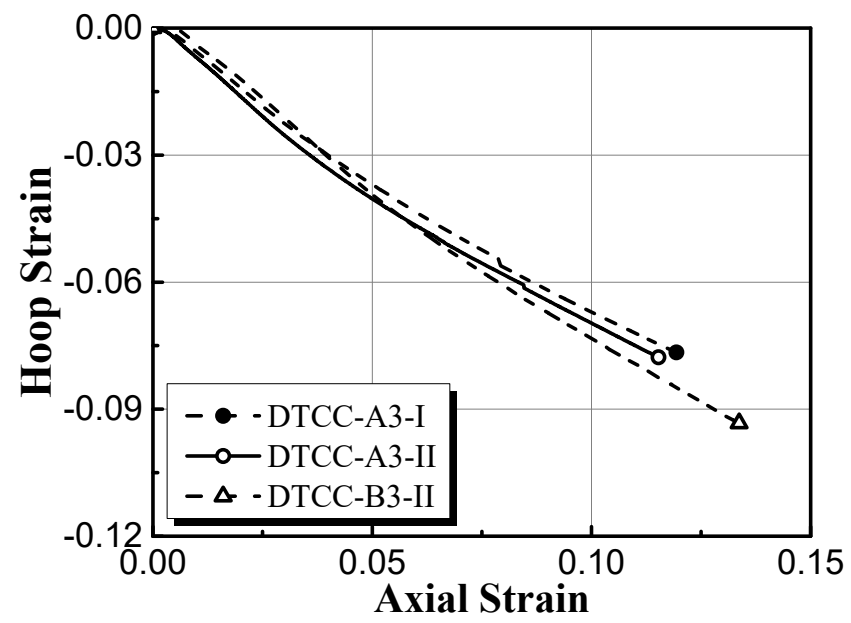

Fig. 16 Effect of steel tube on lateral expansion behavior of DTCCs 